\title{
Microstructural parameters and flow stress in Al-0.13\% Mg deformed by ECAE processing
}

\author{
J.R. Bowen ${ }^{\text {a,* }}$, P.B. Prangnell ${ }^{\text {b }}$, D. Juul Jensen ${ }^{\text {a }}$, N. Hansen ${ }^{\text {a }}$ \\ ${ }^{a}$ Risø National Laboratory, Materials Research Department, Center for Fundamental Research: Metal Structures in Four Dimensions, \\ P.O. Box 49, DK-4000 Roskilde, Denmark \\ ${ }^{\mathrm{b}}$ Manchester Materials Science Centre, UMIST, Grosvenor Street, Manchester M1 7HS, UK
}

Received 25 August 2003; received in revised form 28 January 2004

\begin{abstract}
A high purity Al-0.13 wt.\% Mg alloy was deformed to a von Mises strain of 10 and subsequently annealed at temperatures between 100 and $400^{\circ} \mathrm{C}$ for $1 \mathrm{~h}$. Boundary spacings were measured in orthogonal directions for all boundaries by EBSD and their corresponding $S_{v}$ were calculated over both measurement directions. Boundaries with misorientations $\theta \geq 15^{\circ}$ were used to calculate a standard Hall-Petch strengthening contribution while the boundaries with $\theta$ between $1^{\circ}$ and $15^{\circ}$ were used to calculate a dislocation strengthening contribution. The combined calculations showed close agreement to actual mechanical test data over more than two orders of magnitude of boundary spacing and significant morphology change. The importance of measuring boundary misorientations for the determination of microstructure-property relationships is concluded.

(C) 2004 Elsevier B.V. All rights reserved.
\end{abstract}

Keywords: Aluminium alloy; Strength; Microstructure; ECAE

\section{Introduction}

The Hall-Petch relationship (see Eq. (1)), has been widely used to successfully predict the effect of grain size on the mechanical strength of many metals and alloys:

$\sigma=\sigma_{0}+k d^{n}$

In recent times, with the interest in metals with significantly finer grain sizes than conventional materials, the Hall-Petch relationship has been used to model the extrapolation of grain sizes down to the nanometre scale produced by a wide range of fabrication techniques. With the production of the aforementioned materials, Hall-Petch analyses have illustrated various $k$ values by simple fitting of strength and boundary spacing data (e.g. in aluminium alloys [1]). Typically, in very heavily deformed alloys, the measured $k$ value is significantly higher than that for conventional materials [2] and has also been reported to show deviations from linearity at very fine grain sizes [3].

\footnotetext{
* Corresponding author. Tel.: +45 4677 5795; fax: +45 46775758.

E-mail address: jacob.r.bowen@risoe.dk (J.R. Bowen).
}

In the present work, high strain deformation is used to produce a sub-micron scale microstructure. Such a means to produce fine grain structures is an interesting candidate for exploring the effect of grain size on strength, as sub-micron grained microstructures can be fabricated in materials of simple chemistry with zero porosity. The deformation structure is characterised by electron-backscattered diffraction (EBSD) and its evolution during annealing is followed. The microstructure consists of a mixture of high angle boundaries, as well as dislocation boundaries of low misorientation. The effects thereof on the mechanical properties can be explored, where the high angle boundaries are accounted for by the Hall-Petch relationship and low angle boundaries via standard dislocation strengthening. The calculated results are compared to measured mechanical properties and the agreement is discussed.

\section{Experimental}

A high purity $\mathrm{Al}-0.13 \mathrm{wt} . \% \mathrm{Mg}$ alloy has been deformed to a von Mises strain of 10 by equal channel angular extrusion (ECAE), where the extrusion die had a sharp 
cornered $120^{\circ}$ angle. The billet orientation was maintained constant throughout deformation, which is commonly referred to as Route A [4]. The exact processing details can be found elsewhere [5,6]. The material was annealed at various temperatures between 100 and $400^{\circ} \mathrm{C}$ for $1 \mathrm{~h}$ followed by water quenching. The grain size and morphology was examined by high-resolution EBSD using HKL Technology CHANNEL ${ }^{\mathrm{TM}}$ acquisition software $[5,7,8]$. More detailed descriptions of the as deformed and annealed microstructure morphology can be found elsewhere [9-12].

Boundary spacings have been calculated using the linear intercept method after prior orientation averaging by a modified Kuwahara filter [13] in order to reduce orientation noise inherent in the EBSD data. EBSD data was analysed using VMAP $\odot$ EBSD analysis software [14]. As was performed in [13], EBSD maps illustrating the boundaries only produced after orientation averaging were compared to the pattern quality maps in a qualitative manner to observe any spurious averaging effects. Regions of low pattern quality either represent poor surface quality, high dislocation density or boundaries due to pattern overlap. The pattern quality is especially sensitive to the latter.

Due to the fact that during annealing from the deformed state to a fully coarsened microstructure, a significant change in "grain" aspect ratio is observed, boundaries were characterised in the following manner. In the deformed state, an average grain aspect ratio greater than two defines orthogonal long and short axes (i.e. directions of average maximum and minimum boundary spacing). Intercept distances as well as the misorientation angles of each boundary were measured separately on these orthogonal axes for high angle $\left(\geq 15^{\circ}\right)$ as well as low angle boundaries $\left(15^{\circ}>\theta>1^{\circ}\right)$. The average misorientation of the low angle boundaries was also determined. EBSD maps were collected such that these axes were parallel to the map axes.

The average boundary intercept distance was calculated from the average orthogonal boundary intercept spacings by the stereological relationships below

$$
\begin{gathered}
N_{L}=\frac{1}{\bar{L}}, \quad N_{L_{X Y}}=\frac{1 / \bar{L}_{X}+1 / \bar{L}_{Y}}{2}, \\
\bar{L}_{X Y}=\frac{1}{N_{L_{X Y}}}
\end{gathered}
$$

where $N_{L}$ is the number of boundary intercepts per unit of test line length and $\bar{L}$ is the average boundary spacing. For stereological reasons orthogonal boundary spacings cannot be simply averaged, instead the number of intercepts per unit test line length must be averaged to account for possible differences in test line length on each measurement axis.

Mechanical property data was obtained, either from tensile or compression tests at room temperature. The tensile tests were performed at the former Banbury Alcan International Laboratory. The tensile specimen gauge dimensions were $20 \mathrm{~mm} \times 4 \mathrm{~mm}$ in diameter and were deformed at a strain rate of $8.5 \times 10^{-4} \mathrm{~s}^{-1}$. Strain was determined via a 'clip-on' extensometer. Compression tests were performed on cylindrical specimens $5 \mathrm{~mm}$ in diameter with an aspect ratio of 0.75 with a crosshead speed of $0.05 \mathrm{~mm} / \mathrm{min}$. The strain was determined indirectly from the change in length of an extensometer attached to the load cell and bottom plate, respectively, above and below the platens in contact with the specimen. Typically only one specimen was tested for each annealing condition.
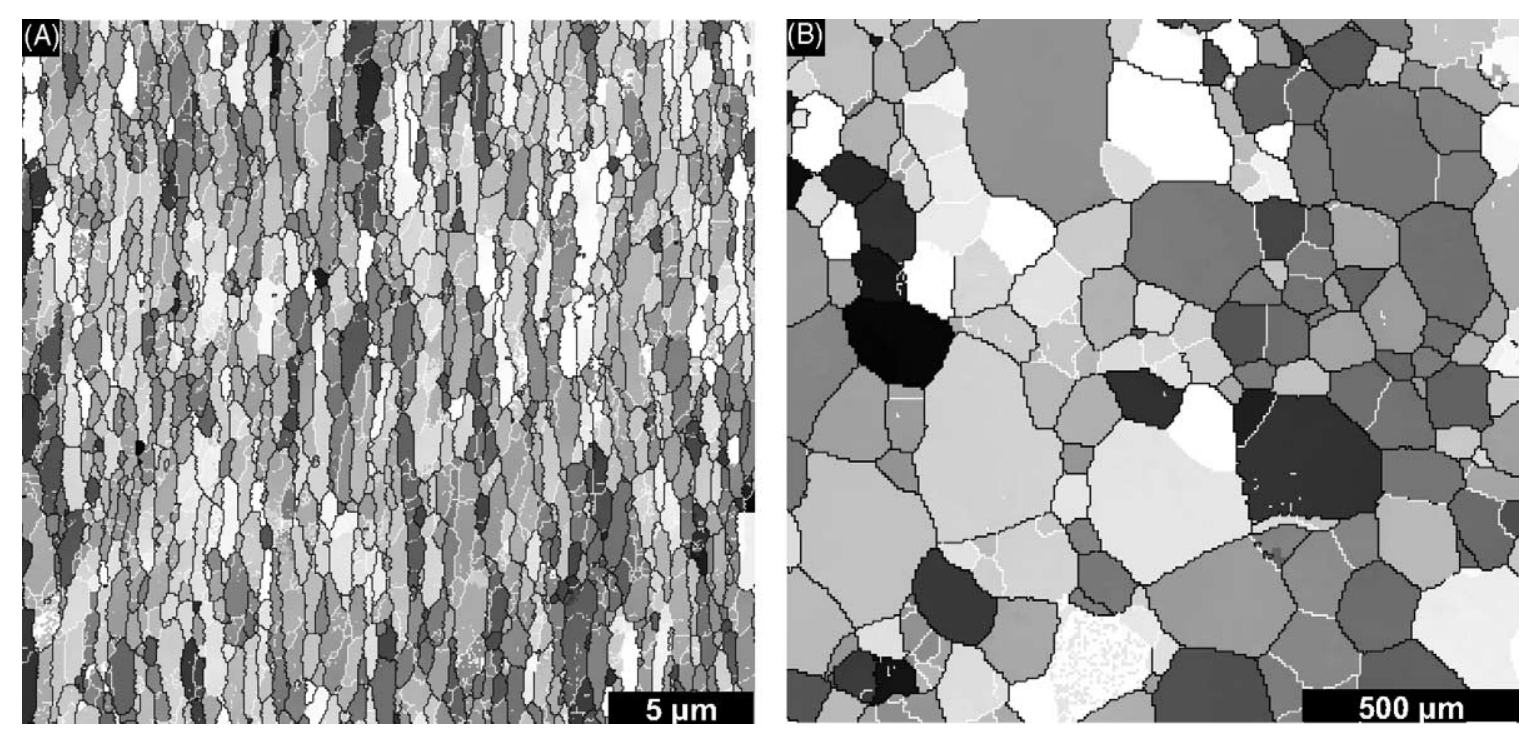

Fig. 1. EBSD maps representing: (A) the as deformed microstructure; (B) after annealing at $400^{\circ} \mathrm{C}$ for $1 \mathrm{~h}$. White lines represent low angle boundaries $\left(15^{\circ}>\theta>1^{\circ}\right)$, black lines high angle boundaries $\left(\geq 15^{\circ}\right)$, and the grey scale is related to crystallographic orientation. The different scales in $(\mathrm{A})$ and (B) represent a change of several orders of magnitude in the grain size. 
Table 1

Measured microstructural parameters and mechanical properties

\begin{tabular}{lcccc}
\hline $\begin{array}{l}\text { Annealing temperature } \\
\left({ }^{\circ} \mathrm{C}\right)\end{array}$ & $\begin{array}{l}\text { Average high angle } \\
\text { boundary intercept }(\mu \mathrm{m})\end{array}$ & $\begin{array}{l}\text { Average low angle } \\
\text { boundary intercept }(\mu \mathrm{m})\end{array}$ & $\begin{array}{l}\text { Average low angle boundary } \\
\text { misorientation }\left({ }^{\circ}\right)\end{array}$ & $\begin{array}{l}0.2 \% \text { proof } \\
\text { stress }(\mathrm{MPa})\end{array}$ \\
\hline As deformed & 0.62 & 1.40 & 5.3 & 196 \\
100 & - & - & - & - \\
125 & 0.77 & 1.75 & 5.3 & 183 \\
150 & 0.87 & 3.07 & 5.6 & $145^{\mathrm{a}}$ \\
175 & 1.50 & 4.70 & 6.4 & $51^{\mathrm{b}}$ \\
200 & 2.91 & 18.60 & 7.3 & 5.4 \\
225 & 5.58 & 39.1 & 6.3 & $30^{\mathrm{c}}$ \\
300 & 27.72 & 102.51 & 8.4 & $28^{\mathrm{c}}$ \\
400 & 161.06 & 362.61 & & \\
\hline
\end{tabular}

${ }^{a}$ UTS occurred prior to $0.2 \%$ uniform elongation, value estimated by projecting the stress-strain curve to $0.2 \%$. The error is estimated to be approximately $5 \mathrm{MPa}$.

b Yield point occurred prior to $0.2 \%$ uniform elongation; the stress was measured at the yield point. The error is estimated to be less than $5 \mathrm{MPa}$.

c Obtained from compression test, the error is estimated to be less than $10 \mathrm{MPa}$, due to difficulty in establishing the proof stress intercept and is expected to be lower than the values given.

\section{Results and discussion}

Typical microstructures are illustrated in the form of EBSD maps in Fig. 1, from (A) the deformed state, and (B) after annealing at $400^{\circ} \mathrm{C}$. Black lines indicate high angle boundaries $\left(\geq 15^{\circ}\right)$, white lines indicate low angle boundaries $\left(15^{\circ}>\theta>1^{\circ}\right)$, and the grey scale is related to orientation. It is immediately apparent from Fig. 1 that the observed change in microstructure dimensions is several orders of magnitude. In the deformed state, an approximate lamellar structure is observed, where the grain aspect ratio is typically greater than 2. After annealing the microstructure has coarsened and become equiaxed. This was observed to start at annealing temperatures of approximately $200^{\circ} \mathrm{C}$.

The measured microstructural parameters and mechanical properties are compiled in Table 1, and are used as input data in the following analysis. The parameter $\bar{L}_{X Y}$ (see Eq. (2)) is used to express the two average boundary intercept spacings given in Table 1. From the data, it can be seen that over the annealing temperature range the average high angle boundary intercept increases from 0.6 to $160 \mu \mathrm{m}$ (see Fig. 1) and a similar increase is seen for the low angle boundaries. Correspondingly, the proof stress is observed to decrease from approximately 200 to less than $30 \mathrm{MPa}$. The average misorientation across low angle boundaries is observed to increase slowly and relatively uniformly from approximately $5^{\circ}$ to $9^{\circ}$. However, it should be noted that this average may be a little inflated due to the EBSD angular resolution, compared to a corresponding measurement by TEM.

Using the measured microstructural data, the strengthening contributions from the two classical boundary types, high and low angle, was calculated using the Hall-Petch relationship to account for the high angle boundary contribution and dislocation strengthening for the low angle boundary contribution respectively, in the combined equation below

$\sigma-\sigma_{0}=k d^{n}+M \alpha G b \sqrt{\frac{1.5 S_{v \mathrm{LAB}} \bar{\theta}}{b}}$
For the Hall-Petch part of Eq. (3), standard values of friction stress $\sigma_{0}$, the Hall-Petch slope $k$ and the grain size exponent $n$ were used. For high purity aluminium with normal grain boundaries these values are, respectively: $20 \mathrm{MPa}, 40 \mathrm{MPa} \mu \mathrm{m}^{1 / 2}$ and $-1 / 2$ [15]. Fig. 2 illustrates, using Eq. (1), the calculated strengthening contribution of the high angle boundaries. The second part of Eq. (3) is the standard expression for dislocation strengthening [16], where $M=3.06$, is the Taylor factor for a randomly textured material. This value is justified by the very weak texture of the material [5]. The factor $\alpha$ is taken as 0.24 $[17,18]$. The shear modulus of aluminium $G$ is taken as $26 \mathrm{GPa}$ and $b$ is the Burgers vector for aluminium, $2.86 \AA$. As the grain interiors are recovered and are relatively free of dislocations, the dislocation strengthening represents the dislocations contained within the low angle boundaries.

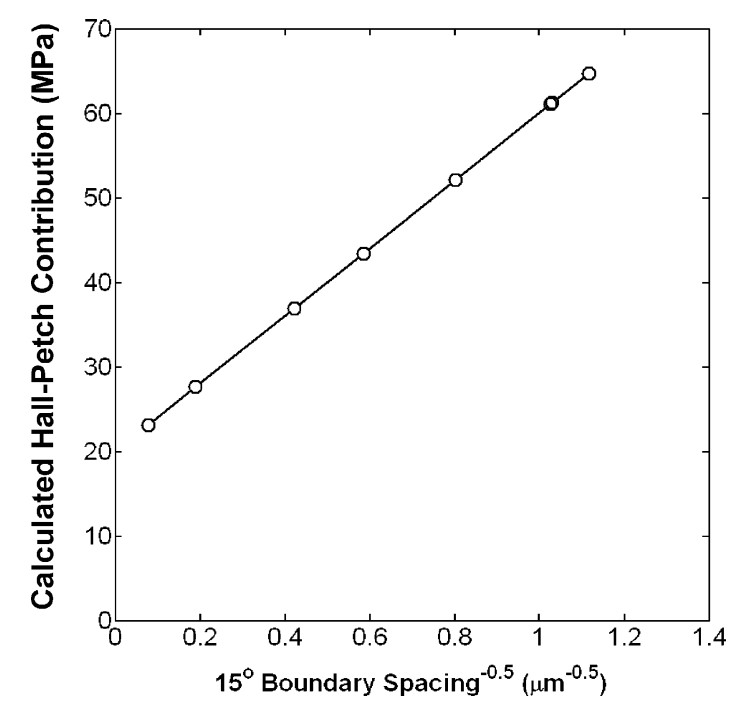

Fig. 2. Calculated Hall-Petch strengthening contribution of high angle boundaries using standard values of friction stress, Hall-Petch slope and boundary spacing exponent (see text for values). 


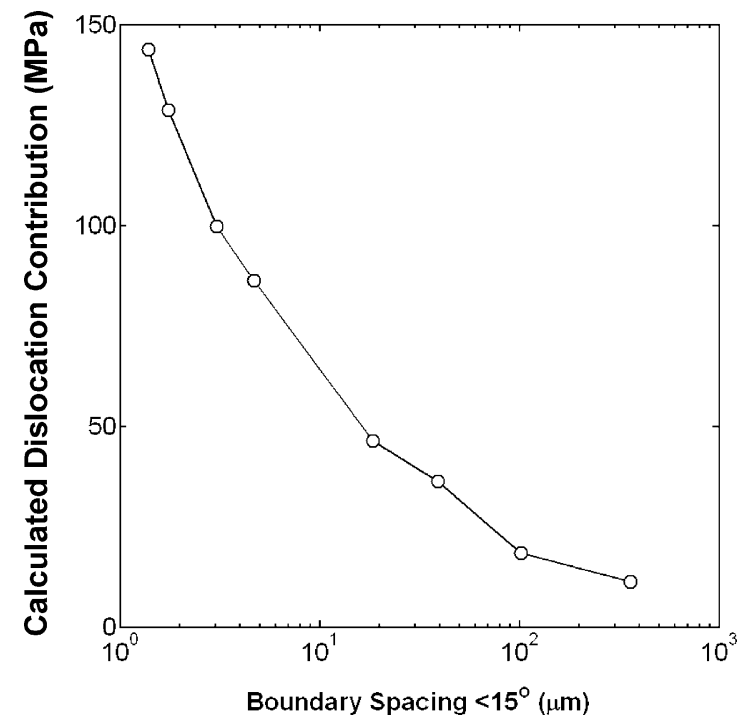

Fig. 3. Calculated strengthening contribution of low angle boundaries via the standard dislocation strengthening mechanism (see text for values).

Values for $S_{v \mathrm{LAB}}$ (boundary length per unit area) were determined experimentally directly from the boundary intercept data of the low angle boundaries only (see Eq. (4)). Lastly, $\bar{\theta}$ expresses the average misorientation of the low angle boundaries only

$S_{v}=\frac{2}{\bar{L}_{X Y_{\text {low angle }}}}$

Fig. 3 illustrates the calculated dislocation related strengthening contribution as a function of the average low angle boundary spacing.
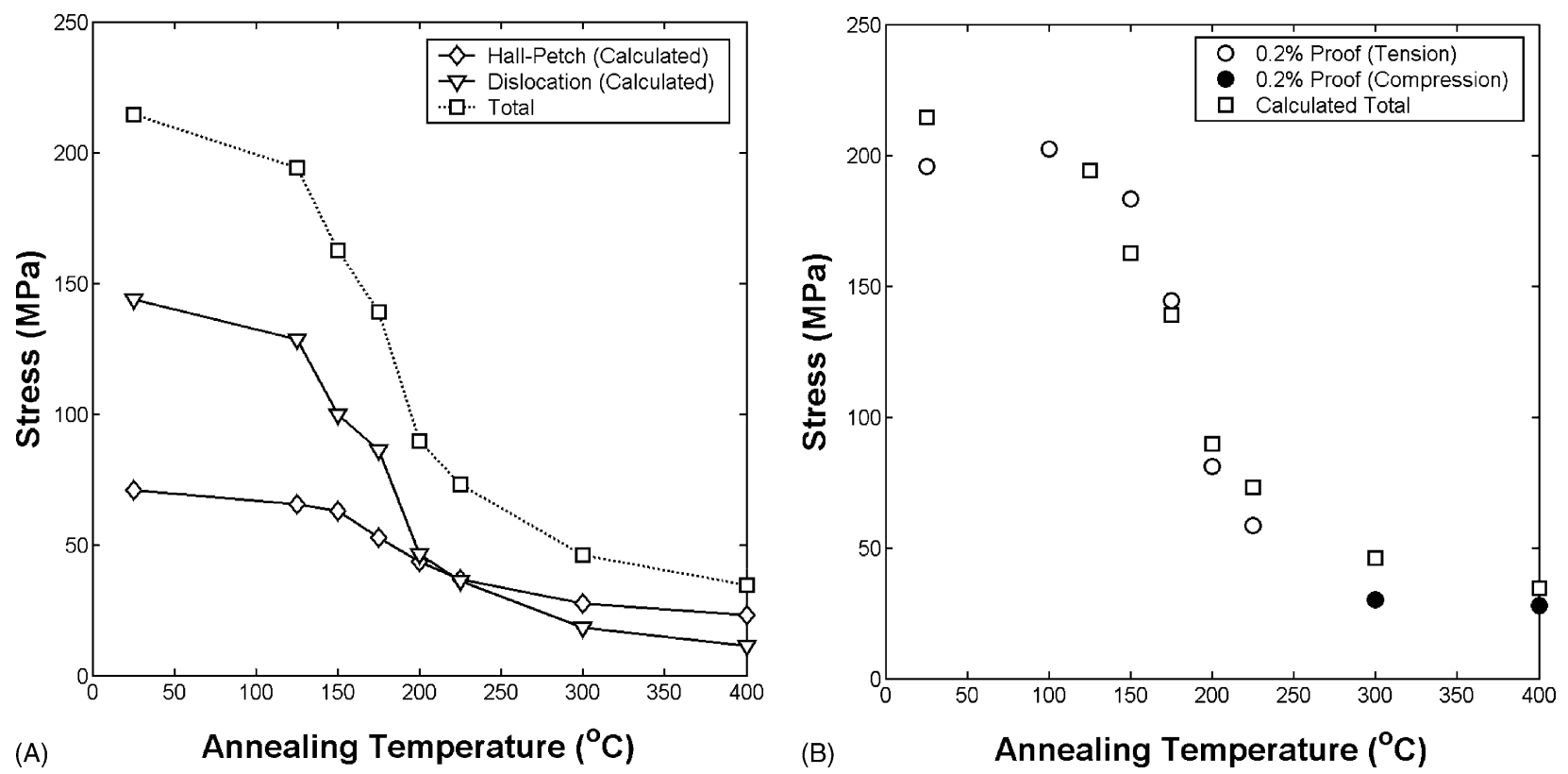

Fig. 4. (A) Calculated Hall-Petch and dislocation strengthening contributions as a function of annealing temperature and their sum, (B) comparison of the calculated strengthening mechanisms in (A), with the measured $0.2 \%$ proof stresses on a universal plot as a function of annealing temperature.
The above-calculated strengthening contributions are then re-expressed individually in terms of the annealing temperature in Fig. 4A. The sum of the contributions is then comseen that the calculated flow stresses agree remarkably with the experimental data within reasonable estimated error limits, with no need for fitting parameters.

The fact that the above analysis holds for the current data, underpins the importance of determining the misorientations of all boundaries in the microstructure and interpreting their strengthening contributions accordingly. The current analysis illustrates that in the heavily deformed and lightly annealed conditions the majority of strengthening is provided by the low angle boundaries despite their small fraction. If the low angle boundaries are ignored, or counted as high angle boundaries, this may give rise to misleading data analysis, and for example, resulting in uncertainty of the Hall-Petch constants.

In the current analysis, the standard definition of the low angle-high angle boundary threshold of $15^{\circ}$ has been used to classify boundaries to their strengthening contributions. This definition, although empirically based on boundary mobility and boundary dislocation structures, is still somewhat arbitrary, and therefore, can be fundamentally questioned in terms of the exact nature of boundary contributions to strengthening. The classification of boundaries to various strengthening mechanisms may also be biased due to experimental technique. The detection of very low angle boundaries in this analysis is restricted by the angular resolution EBSD system; hence the undetected boundaries may obscure the real microstructure-property relationships. However, for the presented analysis it is expected that the pared to the real measured proof stress in Fig. 4B. It can be 
experimental bias has a second order effect on the derived relationship, based upon tests made with different boundary definitions. Furthermore, the microstructure-property relationships in other materials should be determined in this manner to test the analysis presented here.

\section{Conclusions}

Using a stereological approach, the microstructure of a heavily deformed sub-micron grained Al-0.13wt.\% Mg alloy was characterised by EBSD analysis after annealing at various temperatures. The annealed the microstructure was coarsened from a grain size of $\sim 0.6$ to $160 \mu \mathrm{m}$ with a corresponding change in morphology from elongated to equiaxed. Average boundary parameters were extracted for low and high angle boundaries and used for standard dislocation and Hall-Petch type strengthening mechanisms, respectively. The calculated total flow stresses were in close agreement with the measured proof stresses over more than two orders of magnitude of grain size and significant morphology change. The dislocation strengthening contribution of the low angle boundaries despite their low fraction enabled the explanation of the strength in terms of microstructural parameters using standard material constants without fitting parameters. It is concluded that in microstructure-property relationships for deformed and annealed materials, complete characterisation of all boundaries is of vital importance in order to obtain meaningful microstructure-property parameters.

\section{Acknowledgements}

Alcan International is acknowledged for the supply of materials and tensile testing via ultra-fine grained alloys (UFGA) project at the Manchester Materials Science Centre, as well as the EPSRC (grant no. L06997). S. Thorsteinsson is gratefully acknowledged for performing compression testing. We also gratefully acknowledge the support of the Danish National Research Foundation via the Center for Fundamental Research: Metal Structures in Four Dimensions at Risø National Laboratory.

\section{References}

[1] M. Furukawa, Y. Iwahashi, Z. Horita, M. Nemoto, N.K. Tsenev, R.Z. Valiev, T.G. Langdon, Acta Mater. 45 (11) (1997) 47514757.

[2] N. Tsuji, R. Ueji, Y. Minamino, Scripta Mater. 47 (2) (2002) 69-76.

[3] M. Furukawa, Z. Horita, M. Nemoto, R.Z. Valiev, Acta Mater. 44 (11) (1996) 4619-4629.

[4] V.M. Segal, V.I. Reznikov, A.E. Drobyshevskiy, V.I. Kopylov, Russ. Metall. 1 (1981) 99-105.

[5] J.R. Bowen, The formation of ultra-fine grained model aluminium and steel alloys, PhD Thesis, UMIST, 2000.

[6] J.R. Bowen, P.B. Prangnell, F.J. Humphreys, in: J.B. Bilde-Sørensen et al. (Eds.), Proceedings of the 20th Ris $\emptyset$ International Symposium on Materials Science: Deformation-induced Microstructures: Analysis and Relation to Properties, Risø National Laboratory, Roskilde, Denmark, 1999, 269 pp.

[7] F.J. Humphreys, I. Brough, J. Microsc. (Oxford) 195 (1999) 6-9.

[8] F.J. Humphreys, J. Microsc. (Oxford) 195 (1999) 170-185.

[9] A. Gholinia, J.R. Bowen, J.S. Hayes, J. Wang, F.J. Humphreys, P.B. Prangnell, in: N. Hansen et al. (Eds.), Proceedings of the 21st Risø International Symposium on Materials Science: Recrystallization Fundamental Aspects and Relations to Deformation Microstructures, Risø National Laboratory, Denmark, 2000, 345 pp.

[10] P.B. Prangnell, J.S. Hayes, J.R. Bowen, P.J. Apps, P.S. Bate, submitted for publication.

[11] P.J. Apps, J.R. Bowen, P.B. Prangnell, Acta Mater. 51 (10) (2003) 2811-2822.

[12] O.V. Mishin, D. Juul Jensen, N. Hansen, Mater. Sci. Eng. A 342 (1/2) (2003) 320-328.

[13] F.J. Humphreys, P.S. Bate, P.J. Hurley, J. Microsc. (Oxford) 201 (2001) 50-58.

[14] F.J. Humphreys, UMIST, 2000.

[15] N.J. Petch, J. Iron Steel Inst. 174 (1) (1953) 25.

[16] N. Hansen, X. Huang, D.A. Hughes, Mater. Sci. Eng. A 317 (1/2) (2001) 3-11.

[17] N. Hansen, X. Huang, Acta Mater. 46 (5) (1998) 1827-1836.

[18] Q. Liu, X. Huang, D.J. Lloyd, N. Hansen, Acta Mater. 50 (15) (2002) 3789-3802. 